RESEARCH ARTICLE

\title{
Developing FAIR Ontological Pathways: Linking Evidence of Movement in Lidar to Models of Human Behaviour
}

\author{
Laure Nuninger*, Rachel Opitz ${ }^{\dagger}$, Philip Verhagen ${ }^{\ddagger}$, Thérèse Libourel§ ${ }^{\S}$ Clément Laplaigell, \\ Samuel Leturcq", Nathanael Le Voguer", Catherine Fruchart", Žiga Kokalj** and \\ Xavier Rodierll
}

\begin{abstract}
This paper proposes an ontological approach to connect the archaeological topographic evidence for movement in the landscape which can be derived from interpretation and spatial analysis of airborne lidar data with models of movement derived from modeling exercises such as Agent Based Modelling or Cost Path Modelling. This computational ontology enables the investigation of movement and its topographic manifestations in the landscape at various spatio-temporal scales. It creates an explicit framework for accessing meaningful information about movement generated through research using both detection and modelling-led approaches. Developing explicit computational frameworks to provide meaningful context is critical, particularly as remote sensing and modelling projects increase in scale and complexity. The process of developing a computational ontology exposes a deeper underlying issue, and one applicable to many topics we address as archaeologists: if we begin to unpack the concept of 'movement' it is readily apparent that it is a complex phenomenon, like many human habits, and studying it requires drawing together a variety of types of physical evidence and multiple, often competing, theoretical models of human processes and practices. If we wish to make archaeological 'data' on movement available, how do we create appropriate contextual information - really useful metadata - so that this data can be incorporated into the variety of studies for which knowledge of movement is relevant? This is essentially the challenge posed broadly by the FAIR principles, and in particular by the principle of interoperability, which suggests that we "use a formal, accessible, shared, and broadly applicable language for knowledge representation". Rather than simply seeking to fulfill the requirements of an arbitrary standard, attempting to meet the challenge of interoperability provides an impetus and opportunity to attempt to bridge the gap between data and model, and to reconsider how we conceive and represent knowledge in archaeological digital data and modelling projects. This kind of computational ontology, we suggest, can serve as the key for making the data from both these sources actually FAIR.
\end{abstract}

Keywords: pathways; movement; lidar; ontologies; FAIR

\section{Introduction}

What has lidar data ever done for us? The extensive and nuanced collections of microtopographic structures revealed by lidar surveys across large regions should, it seems, enable us to reconsider the way in which societies have shaped their territories because they provide so much detailed data on, quite literally, the shape of places. The features detected through the visual or semi-

\footnotetext{
* CNRS/University of Bourgogne Franche-Comté, FR

University of Glasgow, GB

Vrije Universiteit Amsterdam, NL

University of Montpellier, FR

University of Tours, FR

^ University of Bourgogne Franche-Comté, FR

** ZRC-SAZU, SI

Corresponding author: Philip Verhagen (j.w.h.p.verhagen@vu.nl)
}

automated study of digital terrain models provide indirect information on natural resource use, agro-pastoral and silvicultural practices, and a variety of other activities that intentionally or indirectly shaped the physical landscape. Terrain models derived from lidar data, by removing the current vegetation canopy, offer the possibility to more immediately appreciate the character of past land-use patterns and interrelationships between landscape elements, both of which can be masked by current landcover. In this paper, we argue that the holistic tendency of lidar, in that it records with equal weight a diverse set of landscape elements, combined with stripping back the mask of current forest and woodland vegetation, creates an opportunity to fundamentally rethink our approach to complex behaviours as they are captured archaeologically. The wider variety of features captured encourages broader thinking on the types of archaeological remains that provide data on a given behaviour, which in turn provokes a reconsideration 
of how that behaviour might be modelled. The availability of very high resolution data can drive the reconceptualisations of workflows (Opitz \& Limp 2015) across multiple areas of archaeological prospection. In this context, we use data derived from lidar to reconsider our approach to the study of movement, human, and animal. The relationships between human or non-human behaviours and observed features and modelled features are not straightforward. The goal of this article is to present an operationizable approach that decomposes the broad concept of 'movement' as it is used in archaeology into more specific constituent concepts and builds explicit links to interpretations of how these concepts are expressed in observational data.

\section{Bridging the gap to disentangle pathways}

We begin our reconsideration of studying movement by emphasizing that movement leaves diverse traces in the landscape. Beyond the obvious routeways and corridors, the second-order effects of movement reverberate and structure the landscape, underpinning the logic of the shapes of cultivated fields and spaces between them, and restricting the heights of terraces cut into slopes. Equally, within the direct first-order, remains of movement complexity are present. Lidar data reveals the fabric of many paths that intersect and intertwine according to a complex logic to create the remains we can characterize as "roads." In our attempt to disentangle and interpret these structures, it is essential to focus on the way in which space has been traversed and to interrogate the travel practices of societies, which follow diverse logics. These travel practices and logics ultimately contribute to producing the features observed in contemporary topography. In short, understanding the motivations and travel patterns of past societies allows for a better analysis of land use dynamics because movement underlies the organization of a wide variety of landscape features. The complexity of the evidence observed in lidar data, and the reconsideration of the concepts and models of movement prompted by it, call for a new approach that takes in a broader set of evidence. This approach must go beyond the kind of modelling, essentially based on a cost-benefit hypothesis, which we generally use to simulate invisible or no longer physically extant paths (Verhagen, Nuninger \& Groenhuijzen 2019).

In broadening our set of evidence for movement to take in the diverse remains revealed by lidar surveys, as posited above, we implicitly broaden our conceptual model of the expected physical impacts of movement as a behaviour. This, in turn, prompts reflection on the conceptual and computational models of movement. Computational models of movement generally produce representations of linear routes (Bell, Wilson \& Wickham 2002; Verhagen \& Jeneson 2012; Güimil-Fariña \& Parcero-Oubiña 2015), transit corridors (Whitley \& Hicks 2003; Zakšek, Fovet \& Nuninger 2008; van Lanen et al. 2015), cost of movement surfaces (where cost may be variously defined; Herzog 2013), and accessibility or proximity value weightings for (site) locations (Llobera 2000; Fábrega-Álvarez 2006; Mlekuž 2014). Models of the physical terrain, locations of predefined travel routes or corridors, locations of starting points and destinations, and various models of social and cognitive constraints on and motivations for movement are typical inputs (Bell \& Lock 2000; Whitley et al. 2010; Murrieta-Flores 2014). Our review of dominant computational models of movement (Verhagen, Nuninger \& Groenhuijzen 2019), summarized above, highlights the significant gap between the expected inputs and outputs of these models. These inputs and outputs reflect, on the one hand, data that describe archaeological evidence for movement and, on the other hand, reflect what we expect according to our theoretical models of practices and activities.

This gap effectively creates an interoperability problem between two approaches to studying the same topic. This is important for two reasons: first, the validation of computer models of movement depends on the availability of empirical data, in particular the evidence for ancient movement detected by archaeological investigations. Second, computer models can provide more insight into the structure of ancient path networks and the possible motivations for ancient movement, and thus help us to interpret the material remains found through archaeological survey and excavation. To bridge the gap and attempt to make the data and models from these two methods compatible, we suggest an ontological approach to enable the investigation of movement and its topographic manifestations in the landscape at various spatio-temporal scales. We consider this interoperability problem in the context of the FAIR (Findable Accessible Interoperable Reusable) principles because computational models of movement, their associated inputs and outputs, lidar terrain models and their derivatives, and associated interpreted data are all predominantly, if not entirely, embedded in digital data and systems. In doing so, we suggest that conceptual interoperability, referred to as composability in semantics literature (Tolk and Muguira 2003), must be considered alongside technical data or schema interoperability. In short, technical data interoperability ensures that "systems and services that create, exchange and consume data to have clear, shared expectations for the contents, context and meaning of that data" (http://datainteroperability. org/) while conceptual interoperability, or composability, ensures clear and explicit alignment between the different assumptions and limitations of discrete conceptual models. We propose an ontological mapping approach that can be implemented in a computational ontology, to improve interoperability of diverse data and models to support a new approach to studying movement, with applicability to a broad set of behaviours.

\section{Describing the object and context of the study: what are pathways, and why study them?}

To achieve composability and produce a coherent framework for studying of movements and their transformation over time based on both observed and simulated data, we can begin by explicitly setting out various aspects of our often implicit conceptual frameworks. To do so, we leverage the CIDOC CRM (CIDOC 2015; Doerr 2003; 
Nicolucci 2017) as a conceptual and computational operationalizable framework for describing data and information, material remains, and human behaviours and activities associated with them. The model developed for our study is introduced here to define movement and pathways within our framework, and discussed in more detail below. We begin by building our conceptual model at a high level of generality, considering an area related to a physical manifestation of movement, in the sense intended by the CIDOC CRM's SP1 phenomenal spacetime volume (Hiebel et al. 2015, p. 7-8). SP1 is derived from the more general 'spacetime volume' (E92) (Hiebel et al. 2015, p. 28-29), and is defined as "the true (I) extent of the trajectory of an instance of E18 Physical Thing during the course of its existence, from production to destruction. A fuzziness of the extent lies in the very nature of the phenomenon, and not in the shortcomings of observation (U)." (Hiebel et al. 2015, p.7). This concept allows us to define an area based on the activities, archaeologically manifested as Things (E18; Hiebel et al. 2015, p. 23-24), of a society that inhabited, exploited, and organized an area within a specific temporal span (duration, rhythms...). As archaeologists, we may seek to understand the activities through which a community will shape this space, represent it or even appropriate it. Constructing our framework around this concept enables an approach that takes up the idea of "production of space" as promoted by $\mathrm{H}$. Lefebvre (1974) and more recently by T. Ingold (2011). The physical character of the landscape, its topography, is wellestablished in the literature of archaeology and allied disciplines as a lens through which many of these activities can be inferred (Opitz \& Cowley 2013; Piana et al. 2012). As noted above, movement is a behaviour that results in diverse impacts on the physical landscape, and many of these physical impacts translate into visible physical features of the landscape. We argue that because movement is near ubiquitous, it is one of the core behaviours which shapes the physical landscape, and therefore through which alterations to an area's physical topography, itself essential to the definition of the area, can be understood.

To investigate the relationship between movement and the physical landscape, it is useful to (fuzzily) delimit two types of movement: movement with the primary intention of getting from one place to another and movement within activities related to another primary intention. The first type of movement makes it possible to reshape the landscape to connect distant places physically, and the second to shape the earth's surface through the repeated action of individuals who are mobile while performing different tasks (sensu Ingold 2011). The first of these is often described as transport or travel and the second as movement, and both can produce imprints visible in microtopography. The archaeological traces left by the aggregated movements of different groups are, therefore, very heterogeneous. They range from the road infrastructure consciously built and maintained, to the field boundaries used for local circulation, to an open area where route markers are simple cairns (Aldred 2014). The road network alone explains only part of a society's logic of movement. Considering all the physical features that express non-travel movement, the road network is only the tip of the iceberg. To date, the evidence which reflects alternative movement logics has remained poorly integrated into archaeological analysis of movement (e.g., Llobera 1996; Llobera 2000; Gibson 2007; Cameron 2013). This poor integration is problematic because often it is only possible to reconstruct the logic of occupying space and to understand how changing patterns of movement affect it, through the combination of these different types of physical remains.

In this context, we consider pathways - the physical manifestations of movement - to correspond to all the archaeological entities associated with the concepts of both types of mobility. "Pathways" are therefore not limited to roads or road segments, nor to trails or trail segments, but may consist of piazzas, courtyards, and other open areas, bridges, stairs, boundaries, ditches, river segments or other passages formed by the performance of specific tasks, and even animal trackways inter-mixed with material traces of human movements (Chadwick 2007 and 2016). In the analysis of lidar data, we can only investigate the physical features produced by movement. However, we must specify the conceptual framework that will allow us to recognize and interpret them as potential pathways in order to understand their interconnections and relationships.

For example, the intersection of two features observed on a terrain model derived from lidar (LDTM) could represent three different situations (Figure 1). In the first scenario, multiple paths are established to lead away from a place, that is to say, a meaningful location, in different directions, thus creating a crossroad. Even if this place was later abandoned and all physical traces of it other than the crossroad itself disappeared, the place generated the crossroad. In the second scenario, the intersection of paths provides an opportunity to install a feature like a tree or a cross, or even to establish a dwelling that benefits from the connections created. In this scenario, the presence of
- A place creates a crossroad

- Paths crossing create a place

- Paths intersect but do not cross no meaningful place exists here

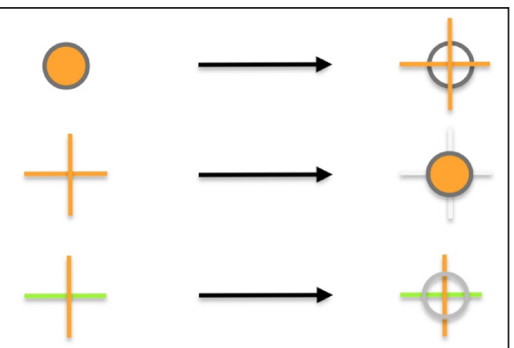

Figure 1: The dilemma of the intersection. 
a crossroad generates a meaningful place. In the last scenario, paths physically intersect without creating a conceptually meaningful crossing. In this third scenario, there is no pre-existing meaningful place that generates a crossroad, nor does the crossing of paths become a meaningful place. An example of this third scenario could be the material evidence of an intersection between a trail used by a cow to graze and a hiking trail used by a human. The intersection is visible in the landscape, but it is not meaningful to either individual. In other words, this material intersection has no reality in terms of flows of movement.

The dilemma of the intersection is a good illustration of the challenges involved in a conjoined analysis of settlement and pathway systems, in particular, when a long period of time is considered. Because paths and places have their own life and their own temporality, their interactions produce complex co-evolutionary processes leaving material traces that are often difficult to disentangle and connect in a meaningful way.

\section{Characterizing the observational data}

Having sketched our conceptual framework, we can consider the elements that are treated as observational data within studies of movement. Physical paths, of the types produced by the first kind of movement defined above, are frequently identified in surveys and landscape studied based on interpretation of LDTMs (e.g., Chase et al. 2011; Vletter 2014; Friedman, Sofaer \& Weiner 2017; Verbrugghe, De Clercq \& Van Eetvelde 2017). At a basic level, these observational datasets are prone to several widely recognized problems, broadly related to chronological uncertainty, bias based on observer background and experience, and the vagaries of topographic preservation (Ainsworth, Oswald \& Went 2013; Fernandez-Diaz et al. 2014; Fruchart 2016; Small 2016).

Beyond these basic problems, pathways, like many other features commonly observed in LDTMs, once recognized, can still be difficult to describe in a way that makes them usable as archaeological observational data. Here we consider that archaeological observational data require a basic spatial, chronological, and conceptual/identification description (Sheth \& Perry 2008; Bala \& Aghila 2019). Many features identified in lidar seem to have good spatial definition, reasonable conceptual definition, and poor chronological definition. Interrogating this generalisation quickly reveals further problems.

The apparent spatial and morphological clarity of features detected in LDTMs has been called sharply into question through the development of semi-automated methods for feature detection, particularly leveraging recent developments in machine learning (e.g., Trier, Zortea \& Tonning 2015; Verschoof-van der Vaart \& Lambers 2019). Several teams have invested in automating feature identification for pathways (notably Vletter 2014) because of the apparent simplicity of pathways' spatial and morphological definition, combined with the practical challenges posed by their quantity and diversity when working to correctly identify, delimit and characterize them over large areas (see e.g., Bofinger \& Hesse 2011). These initiatives further aim to minimize researcher bias in the identification of features (e.g., Banaszek, Cowley \& Middleton 2018). This research has highlighted conceptual complexities in how we delimit, characterize, and identify features like pathways to formulate their locational and morphological definitions. We may be able to describe verbally and with gestures where a path goes, but attempts at explicitly defining its limits on a pixel by pixel or coordinate by coordinate basis, carried out in pursuit of implementing automation, quickly reveal the spatial uncertainties surrounding where the path lies.

Beyond the challenges posed by semi-automation, spatial definition can be unclear because not all pathways are equally visible or recognizable. The physical evidence for pathways can range from monumental constructed roads, such as the Maya sacbe (Chase et al. 2001; Shaw 2012) or Roman imperial roads (Laurence 1999), to ephemeral and unobtrusive trails without any signs of deliberate construction that make use of existing natural landscape features as movement corridors (Gates 2006). These have very different morphological and spatial properties, as well as lifespans, which affects their incorporation into an observational dataset. Beyond the variability in the archaeological evidence, the background, experience, and interests of a researcher condition how they focus their visual attention (Palmer 2013), directly impacting on their capacity to identify features related to a given activity such as stone extraction. This unintentional observer attention bias favours some types of features over others and can introduce prejudices into our perception of the overall landscape shaped by the activity in question. This is particularly relevant for studies of movement because movement is an implicit component of other activities and, consequently, not always a focus of attention, with rare exceptions (e.g., Robin 2002; De Laet et al. 2015). A researcher focusing on the detection of charcoal platforms, for example, may not pay attention to pathways, or even know how to recognize them in a given context or type of data. In contrast, a researcher focusing on detecting pathways may not pay attention to features formed by activities not primarily dedicated to movement, but which are nevertheless used as paths (Erickson \& Walker 2009; Feinman \& Nicholas 2012).

Beyond the problems introduced by the visual characteristics of paths' physical remains and the concentration of visual attention (Halliday 2013), a conceptual problem is present because not all pathways are necessarily recognized as such, since the primary function of the pathway-features may not be related to movement. Field boundaries or terraces, for example, are not designed as movement arteries, yet can develop into paths that connect settlements and fields (Leturcq 2008; Williamson 2016). As noted above, our conceptual definition of a path and our ability to observe and recognize one are closely linked. Further, it remains difficult to connect observed traces to larger landscape-archaeological interpretative frameworks in order to clearly establish their conceptual identifications: what connections did these pathways represent, and to which flows of movement did they belong? This disconnection between the physical evidence and the theoretical discourse on past movement and the flow 
of people, goods, and ideas through the landscape is especially evident when contrasting the practice of lidar prospection to computational modelling of (least cost) pathways. In sum, while many pathways are readily and confidently identified by archaeologists, as with other features commonly recognized in LDTMs, we recognize that this does not constitute an unproblematic dataset.

While the complexities of developing good spatial and conceptual definitions for pathways and other features identified in LDTMs have primarily been emphasized by recent work (see above), the chronologically-challenged character of features identified in LDTMs is a longstanding and widely acknowledged problem (McCoy \& Ladefoged 2009; Hesse 2013; Mlekuž 2013). Pathways, in particular, are challenging in that they are not well suited to dating by morphological analogy and are frequently trans-temporal. The dating and function of physical pathways can only be ascertained reliably through a process of interventions on the ground that extract dateable materials and integrate other sources carrying chronological information. Comparative historical mapping (Vletter \& van Lanen 2018), aerial photography (Verbrugghe, De Clercq \& Van Eetvelde 2017) and archaeological survey data (Fruchart 2016; Crozet, Laplaige \& Rodier 2017) are all used as additional data sets to establish a chronology for the observed features, but this remains challenging.

\section{The difficulties of interrelationships between spatial, chronological and conceptual aspects of observational data}

The conceptual-observational relationship introduced above underlies the core reasons why it is challenging to link detection and interpretation, the task that is the focus of this research. It is only when we take into account knowledge about the various processes responsible for the creation, maintenance, use, and survival of pathways that we can start to consider what it is that we have observed and also what may be missing in the material record.

To summarize, pathways are complex objects built from a set of entities that can have various morphologies. For example, a pathway can be identified based on a succession of flat ground segments, bridges, stairs, and a series of aligned cairns. It is, therefore, less the morphology than the spatial assemblage that enables us to identify a path. To detect pathways, knowledge, and theories about past practices of movement and pathway creation, and on the effects of post-depositional processes, are needed. This contextual information is essential to understand what is observed in LDTMs, and to compare this to other contexts.

We emphasize that formulating the dataset of 'observed pathways' is difficult precisely because it is an observational dataset, and this implies the full cycle of conceptualization of the thing to be observed and interpretation of the observed phenomenon. It should be clear from this discussion that the hermeneutic spiral (Ricoeur 1990) applied to observation during excavation (Hodder 1999) applies equally to the observation of features in the landscape (Ainsworth et al. 2013) and by extension to the digital landscape (i.e., the LDTM).
If excavators interpret at the trowel's edge, archaeologists working across an LDTM to identify features interpret at the interface's edge (see Opitz \& Johnson 2016 for a parallel discussion of work with digital excavation data). Failing to account for the dynamics discussed here would result in impoverished data, a poor understanding of past movement processes, and the absence of controlled intercultural comparisons. Our efforts must, therefore, focus on how to produce practical arrangements that account for the knowledge creation cycle, in particular at the conceptual-observational juncture.

\section{How do we integrate information on pathways obtained through lidar into varied studies of movement?}

To be operational, our approach involves focusing on properties in terms of physical topographic characteristics and basic functions (e.g., depression, alignment, embankment) rather than directly applying the terminology of general categories (e.g., 'hollow way') and culturally specific categories of objects (e.g., sacbe in the Maya world, or elevated causeways linking temples, ceremonial centers or cities). By decomposing the broad concept of 'movement' as it is used in archaeology into more specific constituent concepts, and by building explicit links to interpretations of how these concepts are expressed in observational data, we aim to develop a common conceptual framework. This common framework can be used to design and connect various explicit chains of inference related to the analysis of pathways and past movement flows.

This framework should describe and link practices of movement, morphology (and other material evidence), and the historical and environmental contexts of pathways and their trajectories. It should include all the key elements of the issue and explain their relationships in order to reconstruct one or several logical assemblages that constitute a pathway, an intersection, or even a network or a meshwork.

In order to do so, we take an ontological approach to the problem. This has several advantages: first, it provides a structured, formal way of describing and relating the various terms and knowledge bases used. It also clarifies the structure of the available knowledge. Second, it allows us to consider the various relationships between the terms and concepts used: hierarchical, topological, temporal, and spatial. In this way, we can create the metadata needed to describe and access meaningful information on movement, and strive towards interoperability, as defined under the FAIR principles.

In practice, a research community or group describes their chosen question about past movement using terms and ideas drawn from several published studies. The published studies serve as sources from which the research group can assemble a broad 'world' of context-specific concepts used to address a single, more global, idea. These concepts are then organized, to connect what was observed, which we think of as things, or nouns, with how we understand the activities that produce them, which we think of as verbs. To create an operational model, we proceeded in three steps. We first analyse articles for the 
language used to describe landscape features and actions of movement, then we produce a graph model of the language used, and finally, we formalize this into an ontology. By drawing together and studying the language used in multiple case studies, this exercise attempts to define a conceptual model that is implicitly broadly shared by the research community interested in the question but does not rely on a predefined model. Rather, domain and question specific ontological models are developed to address specific research agendas.

In developing domain and question-based ontologies, crucially, we make use of existing conceptual reference models such as CIDOC CRM (Doerr 2003; Nicolucci 2017), cross-mapping our ontology's domain-specific entities and properties to those described in the CIDOC. This mapping to a shared community standard increases the usefulness of the specialized ontology, as it can be made interoperable with related systems, which also make use of the CIDOC CRM.

By proposing an approach that relies on the formalization of concepts and alignment with shared community standards for describing knowledge domains, we are not aiming to encourage the mechanisation of the interpretive process. Instead, we underline the creativity, discussion, and heuristic processes emergent through the practice of creating an ontology, which enables us to better understand and map the limitations and potential of our knowledge domain. In short, the practice of ontology creation and mapping is a heuristic tool that can help us in the process of interpretation. Importantly, the resulting ontology provides a formal framework that can be used to share data that remains flexible as different projects may map their own data differently depending on the context of the research.

The heuristic aspect of the ontological approach is particularly favourable to the development of a cross-cultural analytical framework. Through a qualitative analysis of research data, reports, and scientific articles, the group extracts the various concepts that have been used to describe pathways, their characteristics, and their function. This leads to a stage of concept mapping, where various terms and concepts will be classified and their relationships will be established. In particular, it is the linking of concepts that make it possible to identify the key invariant points, from one study to another, which in turn allows a logical understanding of past movement flow. The way concepts are linked provides a common definition to assemblages of various morphological, temporal, spatial, and functional characteristics, which are not necessarily the same over various geographical zones or even over the whole of the geographic area where they appear.

Starting from various case studies from medieval France (Leturcq 2008), the Ancestral Pueblo in the southwest of the United States (Friedman, Sofaer \& Weiner 2017) and the Maya world in Belize (Chase \& Chase 2001; Chase et al. 2011), we have experimented with this approach in multiple workshops with diverse participants, including experienced and novice lidar users, students, academic researchers, and heritage managers. Tools, ranging from pen and paper or post-it notes to spreadsheet forms and schema modelling software (like the UML software package
yEd; https://www.yworks.com/products/yed), can be used in the exercise of collective ontology development. While discussing the definitions of concepts and their relations can lead to somewhat different outcomes in different groups, opinions on the general structure often quickly converge. Where views remain divergent between groups, alternate ontologies may be developed, and the point of divergence becomes the basis for further study and debate.

This exercise can be repeated for all types of pathways, each time leading to a different set of characteristics that are nevertheless structured similarly. The step of formalizing this into a UML schema representing the structure of the knowledge is then relatively easy and help its formalization within an ontology editor (such as Protégé: https:// protegewiki.stanford.edu/wiki/Main_Page). Using a logical language such as OWL (https://www.w3.org/2001/ sw/wiki/OWL) provides the possibility to visualize concept hierarchies.

\section{From headlands to pathway systems: an illustration of the approach}

As an illustration of this approach, we will use an example from Samuel Leturcq's work on the organization of agricultural territories in the Beauce region (France) during the Medieval and Early Modern periods (12th-17th centuries). This study was partly focused on the organization of the openfield landscape, notably on the distribution of the transportation routes in the agricultural territories of Toury en Beauce (Leturcq 2008). The study of old maps revealed a dispersed local road network in extensive continuous agricultural areas composed of contiguous parcels. This situation raised the fundamental question: how can a peasant reach plots of land enclosed within a field system composed of a large number of small contiguous fields, without any pathways built within the area? To answer this question, it was necessary to investigate the peasants' practices of cultivating their land from an individual and a collective point of view. This investigation raised further questions connected to the social management of space: How are fields physically delimited? Where were the peasants permitted to cross the cultivated area by the community?

In this openfield region, farmers were using a style of turnplough or a plough-tail (a type of ard-plough) that is held at an angle while ploughing the soil in order to push the earth to one side and the other (Laligant 2007). Rows were ploughed in straight lines, and the ploughs were turned at the boundaries of the field. As the land was tilled, the soil was moved and progressively accumulated on the edge of the field. Over the years, this accumulation of soil at the edge of each field developed into raised beds, or headlands, which can still be recognized in Beauce, as in many other regions (McOmish 2011; Hall 2014) and clearly visible on a LDTM (Figure 2).

The visible boundaries of the community's cultivated lands are, consequently, materialized by the headlands. In cases where the direction of ploughing is regulated by the community, as is common in medieval northwestern Europe, the headland will gradually become a continuous border along numerous contiguous fields, connecting fields located at the interior of a block of fields (Zadora-Rio 


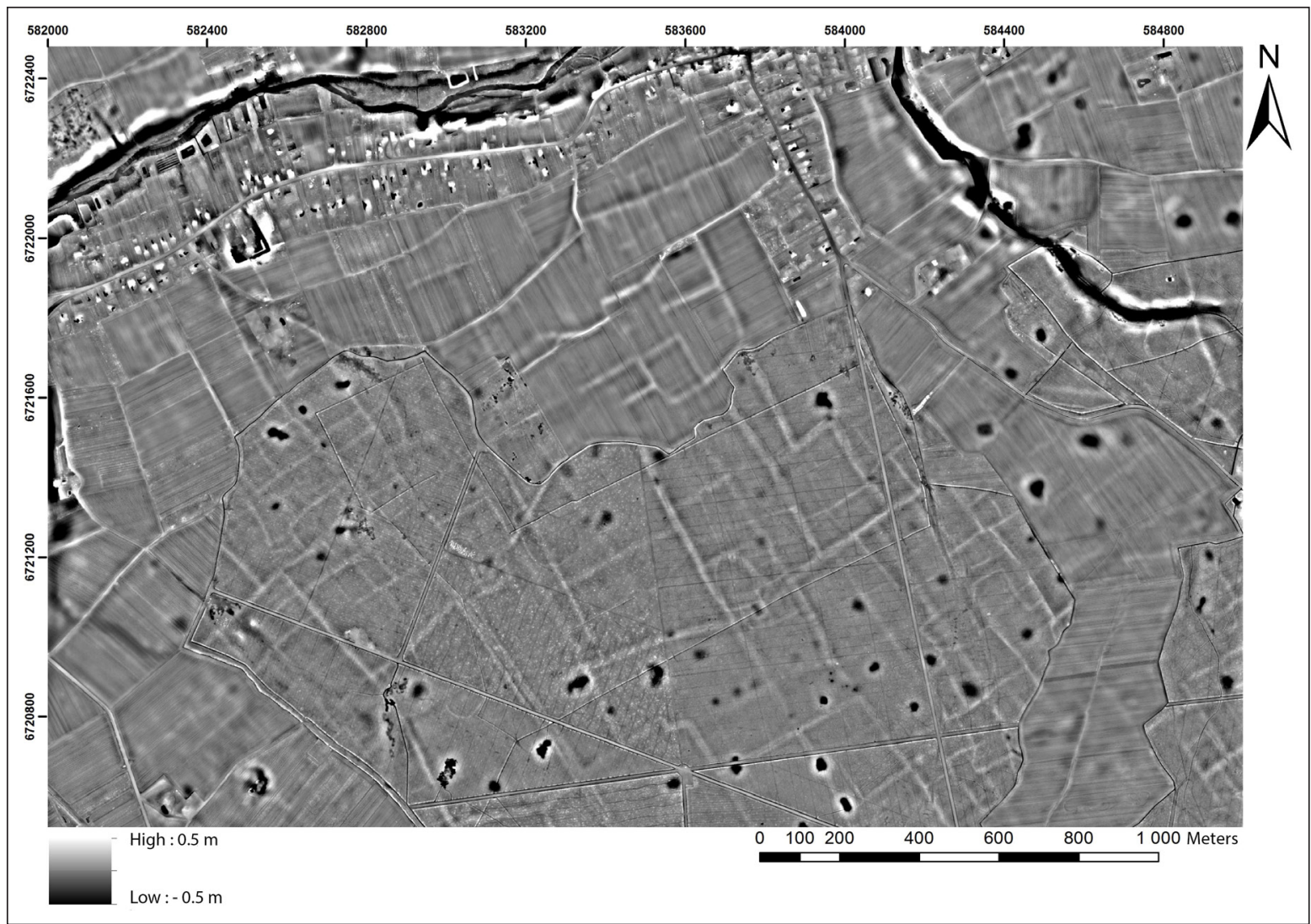

Figure 2: Topographic evidence of headlands visible on a LDTM (linear banks in white), visualised as a Local Relief Model stretched between -0.5 and $0.5 \mathrm{~m}$. This example is located at the border of the forest of Boulogne (Huisseau-sur-Cosson, Loir-et-Cher, France). Source: SoLidar Project.

1991) (Figure 3). Written historical sources state that the borders of some fields can be used as paths by farmers to access their fields (Leturcq 2008). In this region, the practice is further evidenced by the term sommiere, which was used in the language of Toury en Beauce's peasants to refer to the headlands, and is sometimes connected to the term for a path in the medieval and modern "Terrier," which is a register of lands belonging to a single landowner (Leturcq 2008). The accumulated evidence suggests that the headland-as-border developed into a structure that facilitated movement between farms, fields and settlements. It was available for use as a path, in particular when the fields contain growing crops and under conditions defined by the village community, without having been intentionally created as such. Despite a lack of textual evidence in other studies, we can infer that headlands also supported the flow of movement of farmers elsewhere. Evidently, when fields were empty farmers could also walk across the field. Our modelling exercise does not take into account this possibility because it did not visibly alter the topography.

If we were to look at the LDTM without knowing this, we would see a patchwork of raised field boundaries, without clear evidence for their use as pathways. Furthermore, historical maps only show us the roads and paths that were used for moving between settlements, thus underestimating the spatial extent and misinterpreting the configuration of movement, as Leturcq's study (2008) demonstrates. It is only after associating the road system with the headlands that we obtain a complete picture of the flow of movement

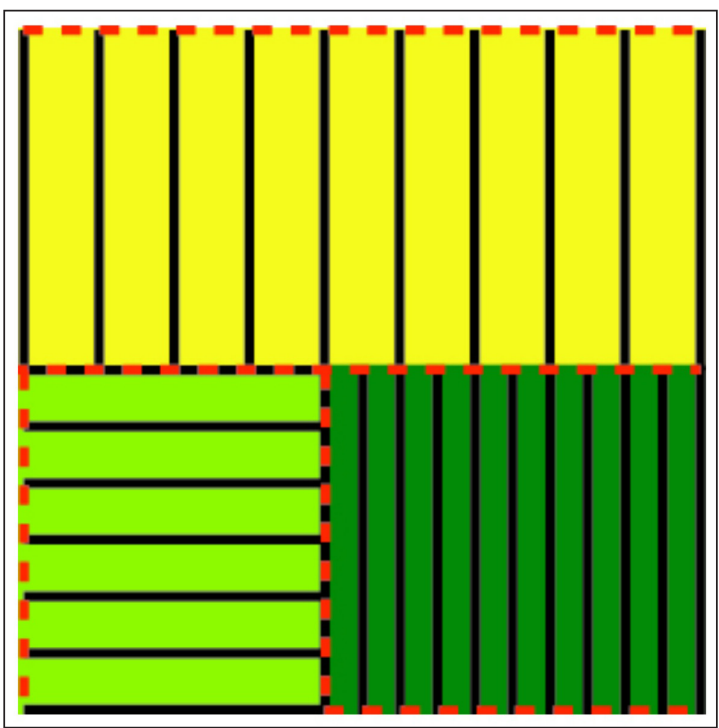

Figure 3: Schematized field system. Black = parcel, yellow to green $=$ parcel aggregates (districts) in a field system (the whole area), red = field limits used as potential path.

in the network of rural communities (Figure 4). It is thus only by bringing together the observed material record and the knowledge of movement practices that we can start to map and understand the actual movement patterns. The ontological approach provides a formal framework.

In this respect, we can start by formalizing the components of the agrarian landscape into a UML schema 
(Figure 5). The components are linked by processes. For example, the farmer can access parcels using paths named 'access path' in this scheme. These could be either headlands used as pathways or other, more formalized path as roads or routes mentioned on the map. The organisation of the districts on the landscape will structure the flow of movement and complements other movement arteries.

The analysis with a UML graph permits the construction of a knowledge structure using an ontology editor (Figure 6). Each object is clearly described with its properties, its domain, and the relations with other objects. Knowledge is thus structured in related classes, which allows us to connect important details, such as the traction of the turnplough, to a more general view of the landscape, which is important for the study of the movement system. Structuring knowledge and expressing it in this type of ontological description allows us, on the one hand, to reconnect elements of an analysis to a body of knowledge and, on the other hand, to transfer conceptual frameworks between case studies more easily.
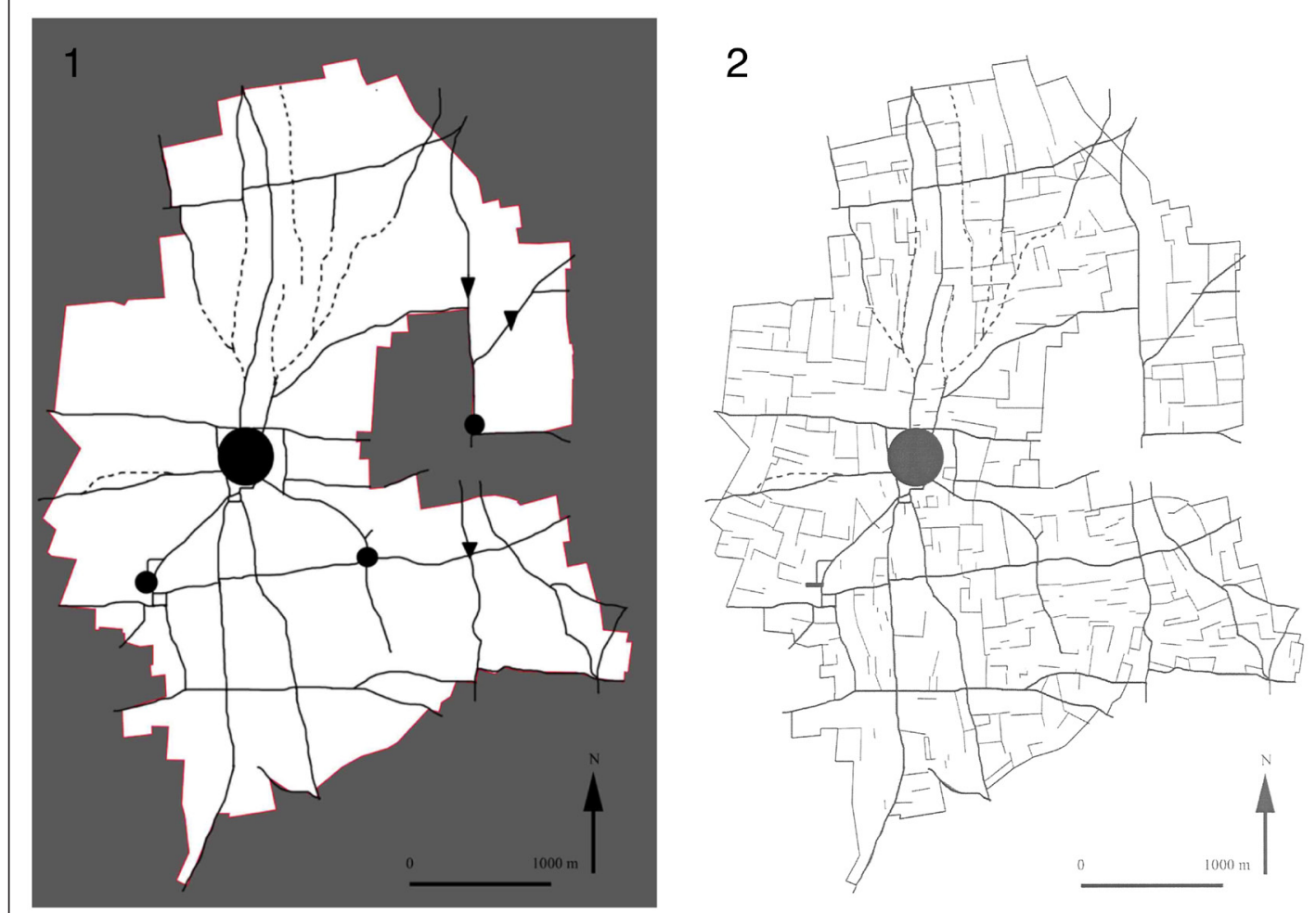

Figure 4: 1) Map of the road network mentioned on the plan of the "Terrier" in 1696, 2) Map of the road network, and the headlands declared by the "tenanciers" (tenants) in 1696. Source: Leturcq (2008).

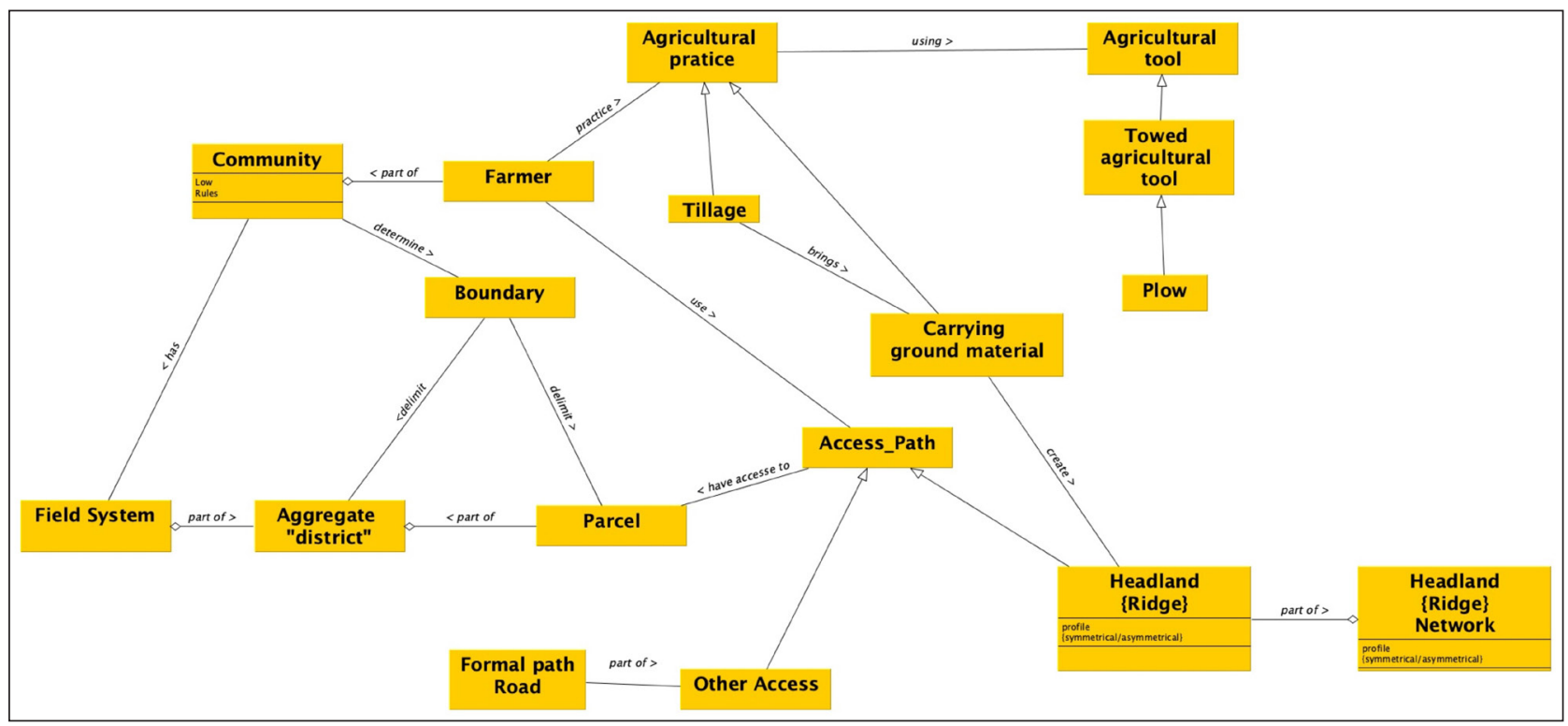

Figure 5: Example of mapping the headlands system with a UML schema editor. This is a simplified model focusing on topographical observations only. 


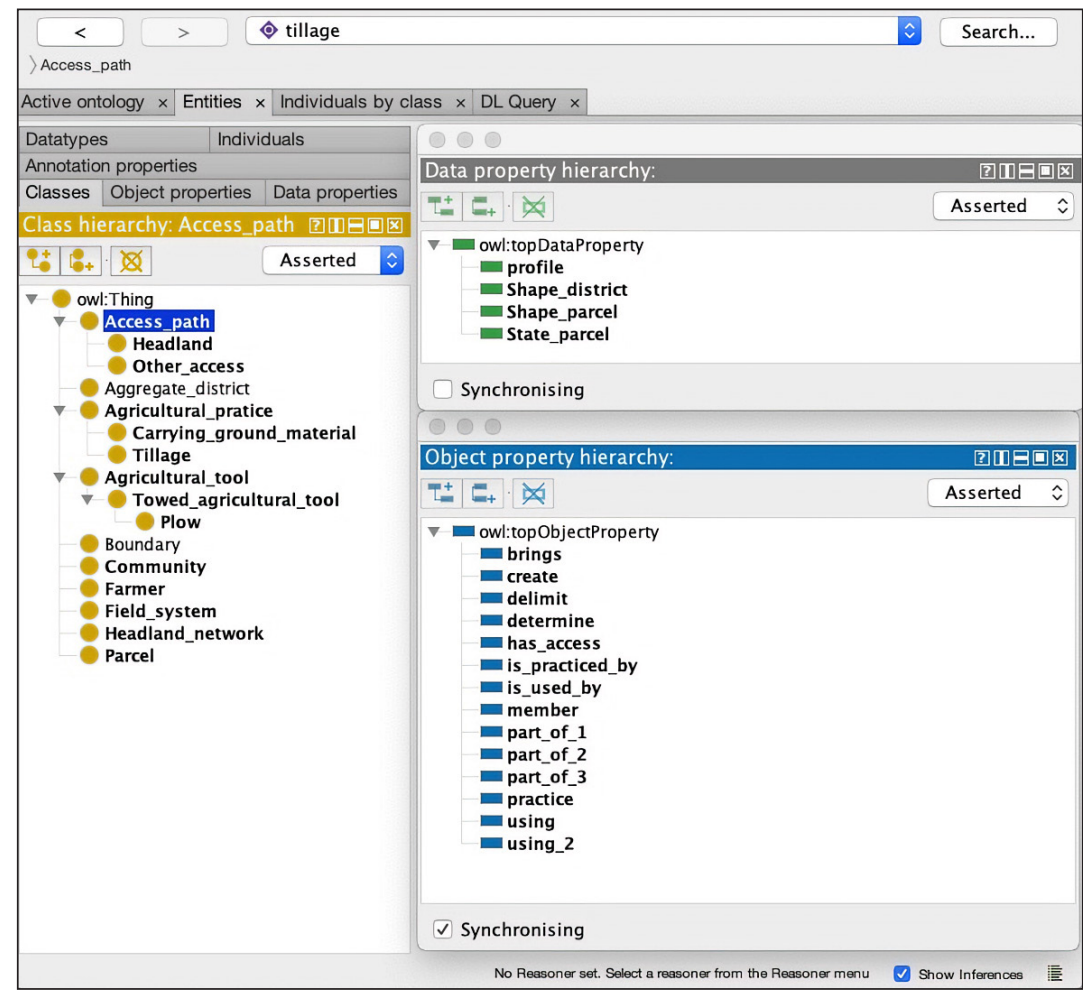

Figure 6: Example of formalization of the headlands system using an ontology editor (Protégé).

In our example, the access path is now better defined and this allows us to better model the local movement network of the farmers. We now have information on its morphology, its relation to the social and landscape organisation, and its use and temporality, linked to the rules of the agrarian community. Future exercises of ontology development might permit us to better choose the parameters for our models. The same ontology and mapping set provides a framework for an informed interpretation of the results of either a visual interpretative survey or computational modelling exercise. Focusing on the key element designated as "access path" enables us to include similar structures of movement flow based on other types of objects like stairs, terraces, and causeways, for example.

Mapping the logic schema to CIDOC CRM standards and to the observational data are the next steps in the process. The CIDOC mapping is the key piece of intellectual work necessary to support interoperability in the FAIR sense because it connects domain and case specific explicit ontologies to a generalized shared ontology that serves as an agreed community standard on cultural heritage.

In order to undertake the CIDOC mapping process, it is necessary to map terms used in the specific group ontology to one or more CIDOC elements (E) or properties (P), provide an explanation of the mappings, and note any instances where the mapping falls outside the defined CIDOC scope. To undertake the data mapping process, it is also necessary to map data elements (D) or queries that aggregate data elements (QD) to elements $(\mathrm{E})$ in the question specific ontology developed by the group. If incorporating computational models of movement, an exercise not yet formally undertaken by this group, we suggest the parallel process would rely on the mapping of rules and entities. Recognizing that these mappings are themselves interpretations, we advocate for the inclusion of basic references and citations in the explanatory notes.

\section{Conclusions: What can we do with it?}

The process of developing and formalizing domain or question specific ontologies, mapping data as defined in a given project to them, and mapping the ontologies themselves to a shared community standard like the CIDOC CRM provides several useful mechanisms for the interpretation of lidar in an archaeological or landscape context. The practice of ontology-making encourages creative heuristic discourse around behaviours and concepts like 'human movement' and material evidence for it. The domain or question specific ontology provides a framework for structuring interpretations of observed features or feature collections. The future mappings to the CIDOC CRM should play the important role of making interpretations based on observational data, which are predominantly individual or project-specific and unsuitable to strict standardization, more interoperable in the FAIR sense and therefore more readily and productively integrated with other data sources, analytical methods, and modelling approaches.

After over a decade of increasingly widespread use of lidar data in archaeological studies of landscapes, the implications of the shift in the practice of archaeological topographic interpretation from one based primarily on the work of individuals or small teams undertaking interpretive work on the ground to one that makes extensive use of digital data and workflows to undertake this same interpretive work continue to emerge. Both approaches often carried out in combination within a given project, are embedded in the cycle of observation, interpretation, and depiction (Opitz \& Cowley 2013) and should be 
informed by domain knowledge of social practices, the underlying physical character of the terrain, and historical trajectories of human activity, land use, and environmental processes. The exercise of formally connecting this complex domain knowledge with interpretations of observational datasets through ontological mapping provides a new strategy for the practice of LDTM interpretation. In this paper, we have shown how mapping of domain knowledge around (primarily human) movement can be used to connect observed physical features in an LDTM with activities that create them. Similar work might be undertaken to develop and cross-map ontologies for a variety of other behaviours that shape the physical landscape in diverse ways such as cultivation, irrigation, and other forms of land management, or equally encampment and inhabitation.

The discourse surrounding the differences in these practices and synergies between them has raised awareness of the diversity of approaches taken to the interpretation of archaeological topography. It also emphasized the importance of taking into consideration the background and knowledge base of different interpreters and teams. This highlighted (again) the significant challenges surrounding the creation of survey results that can be usefully combined and integrated. At the same time, the increasing importance of digital workflows and data in archaeological landscape studies, together with broader trends toward open data within the digital archaeology community and within the provision of lidar data in Europe, have prompted efforts to make the data emerging from studies of archaeological topography usable within the broad principles of the open data/open knowledge community. Framing the ontological development and mapping approach proposed here within the discourse surrounding FAIR data principles, with an emphasis on interoperability, provides a useful mechanism for motivating the shifts in practice needed to address contemporary challenges in the archaeological study of landscapes, leveraging the growing availability of large lidar datasets and the community's recognition of the complexities of interpreting them.

\section{Acknowledgements}

The research for this paper was partly made possible through the Movescape project thanks to a PICS grant awarded to Laure Nuninger by CNRS, a CLUE+ grant to Philip Verhagen by Vrije Universiteit Amsterdam and funds from ZRC-SAZU to Žiga Kokalj for organizing TRAIL2018 (Postojna, Slovenia).

Travel funds were also made available by the University of Glasgow and by the University of Tours (thanks to the SoLidar project, co-organiser). Movescape workshops were organised in Besançon (MSHE C.N. Ledoux, CNRS), in Tours (MSH Val de Loire and CITERES, University of Tours), in Amsterdam (Vrije Universiteit Amsterdam), in Glasgow (University of Glasgow) and opened to a larger public in Atlanta (CAA2017) and in Postojna (TRAIL2018). Publication funds were provided by the European Research Council (ERC) under the European Union's Horizon 2020 research and innovation program (grant agreement No 639828).

\section{Competing Interests}

PV is managing editor for JCAA, which is on a voluntary basis. He has not been involved in the editing process for this paper. All other authors have no competing interests.

\section{References}

Ainsworth, S, Oswald, A and Went, D. 2013. Remotely acquired, not remotely sensed: using lidar as a field survey tool. In: Opitz, RS and Cowley, DC (eds.), Interpreting archaeological topography. 3D data, visualisation and observation. AARG Occasional Paper. Oxford: Oxbow Books. pp. 206-22. DOI: https:// doi.org/10.2307/j.ctvh1dqdz.22

Aldred, 0. 2014. An Archaeology of Movement: a methodological study. PhD thesis. Reykjavík: University of Iceland.

Bala, PS and Aghila, G. 2019. Q-Genesis: Question Generation System Based on Semantic Relationships. In: Advances in Big Data and Cloud Computing. Springer. pp. 509-517. DOI: https://doi. org/10.1007/978-981-13-1882-5_44

Banaszek, t, Cowley, D and Middleton, M. 2018. Towards National Archaeological Mapping. Assessing Source Data and Methodology-A Case Study from Scotland, Geosciences, 8(272). DOI: https:// doi.org/10.3390/geosciences 8080272

Bell, T and Lock, G. 2000. Topographic and cultural influences on walking the Ridgeway in later prehistoric times. In: Lock, G (ed.), Beyond the Map. Archaeology and Spatial Technologies. NATO Science Series. Series A: Life Sciences. Amsterdam: IOS Press/Ohmsha. pp. 85-100.

Bell, T, Wilson, A and Wickham, A. 2002. Tracking the Samnites: Landscape and Communications Routes in the Sangro Valley, Italy. American Journal of Archaeology, 106(2): 69-186. DOI: https://doi. org/ $10.2307 / 4126242$

Bofinger, J and Hesse, R. 2011. As far as the laser can reach... - Laminar analysis of LIDAR detected structures as a powerful instrument for archaeological heritage management in Baden-Württemberg, Germany. In: Cowley, D (ed.), Remote Sensing for Archaeological Heritage Management. EAC Occasional Paper. Brussels: EAC. pp. 161-172.

Cameron, CM. 2013. How People Moved among Ancient Societies: Broadening the View, American Anthropologist, 115 (2): 218-231. DOI: https://doi. org/10.1111/aman.12005

Chadwick, AM. 2007. Trackways, hooves and memorydays-human and animal memories and movements around Iron Age and Romano-British rural landscapes. Prehistoric Journeys. Oxford: Oxbow. 131-152.

Chadwick, AM. 2016. Foot-fall and hoof-hit. Agencies, movements, materialities, and identities; and later prehistoric and Romano-British trackways, Cambridge Archaeological Journal, 26(1): 93-120. DOI: https://doi.org/10.1017/S095977431500027X

Chase, AF and Chase, DZ. 2001. Ancient Maya Causeways and Site Organization at Caracol, Belize, Ancient 
Mesoamerica, 12(2): 273-281. DOI: https://doi. org/10.1017/S0956536101121097

Chase, AF, Chase, DZ, Weishampel, JF, Drake, JB, Shrestha, RL, Slatton, KC, Awe, JJ and Carter, WE. 2011. Airborne LiDAR, archaeology, and the ancient Maya landscape at Caracol, Belize. Journal of Archaeological Science, 38(2): 387-39. DOI: https:// doi.org/10.1016/j.jas.2010.09.018

CIDOC. 2015. Current Official Version of the CIDOC Conceptual Reference Model. The version 6.2 of the reference model.

Crozet, A, Laplaige, C and Rodier, X. 2017. Une approche multidisciplinaire de la fabrique des paysages dans la longue durée dans les forêts de Blois, Russy, Boulogne et Chambord (Loir-et-Cher). Projets de paysage, 16: 1-24.

De Laet, V, Van Loon, G, Van der Perre, A, Deliever, I and Willems, H. 2015. Integrated remote sensing investigations of ancient quarries and road systems in the greater Dayr al-Barsha Region, Middle Egypt: A study of logistics. Journal of Archaeological Science, 55: 286-300. DOI: https://doi.org/10.1016/j. jas.2014.10.009

Doerr, M. 2003. The CIDOC Conceptual Reference Module: an ontological approach to semantic interoperability of metadata. AI Magazine, 24(3): 75-92. DOI: https://doi.org/10.1609/aimag.v24i3.1720.

Erickson, CL and Walker, JH. 2009. Precolumbian causeways and canals as landesque capital. In: Erickson, CL, Darling, JA and Snead, JE (eds.), Landscapes of movement. Trails, Paths, and Roads in Anthropological Perspective. Philadelphia: University of Pennsylvania Museum of Archaeology and Anthropology. pp. 232-252.

Fábrega-Álvarez, P. 2006. Moving without destination. A theoretical GIS-based determination of movement from a giving origin. Archaeological Computing Newsletter, 64: 7-11.

Feinman, GM and Nicholas, LM. 2012. Compact versus dispersed settlement in pre-Hispanic Mesoamerica: The role of neighborhood organization and collective action. In: Smith, ME (ed.), The neighborhood as a social and spatial unit in Mesoamerican cities. Tucson: The University of Arizona Press. pp. 132-155.

Fernandez-Diaz, J, Carter, W, Shrestha, R, \& Glennie, C. 2014. Now you see it... now you don't: Understanding airborne mapping LiDAR collection and data product generation for archaeological research in Mesoamerica. Remote Sensing, 6(10), 9951-10001. DOI: https://doi.org/10.3390/rs6109951

Friedman, RA, Sofaer, A and Weiner, RS. 2017. Remote Sensing of Chaco Roads Revisited. Lidar Documentation of the Great North Road, Pueblo Alto Landscape, and Aztec Airport Mesa Road. Advances in Archaeological Practice, 5(4): 365-381. DOI: https:// doi.org/10.1017/aap.2017.25

Fruchart, C. 2016. Utilisation de plans forestiers XVIIIeXIXe siècles pour une étude archéologique des paysages passés de la forêt de Chailluz (Besançon): l'exemple d'un réseau viaire. Bulletin du centre d'études médiévales d'Auxerre|BUCEMA, (Hors-série $\mathrm{n}^{\circ}$ 9). DOI: https://doi.org/10.4000/cem.13789

Gates, JE. 2006. Hidden passage: Graeco-Roman roads in Egypt's eastern desert. In: Robertson, EC, Seibert, JD, Fernandez, DC and Zender, MU (eds.), Space and Spatial Analysis in Archaeology. Calgary: University of Calgary Press. pp. 315-322. DOI: https://doi. org/10.2307/j.ctv6gqr9h.35

Gibson, E. 2007. The Archaeology of Movement in a Mediterranean Landscape. Journal of Mediterranean Archaeology, 20(1): 61-87. DOI: https://doi. org/10.1558/jmea.v20i1.61

Güimil-Fariña, A and Parcero-Oubiña, C. 2015. "Dotting the joins": a non-reconstructive use of Least Cost Paths to approach ancient roads. The case of the Roman roads in the NW Iberian Peninsula. Journal of Archaeological Science, 54: 31-44. DOI: https:// doi.org/10.1016/j.jas.2014.11.030

Hall, D. 2014. The open fields of England. Oxford: Oxford University Press. DOI: https://doi.org/10.1093/acpr of:oso/9780198702955.001.0001

Halliday, S. 2013. I walked, I saw, I surveyed, but what did I see?... and what did I survey. In: Opitz, RS and Cowley, DC (eds.), Interpreting archaeological topography. 3D data, visualisation and observation. AARG Occasional Paper. Oxford: Oxbow Books. pp. 63-75. DOI: https://doi.org/10.2307/j.ctvh1dqdz.10

Herzog, I. 2013. Theory and Practice of Cost Functions. In: Contreras, F, Farjas, M and Melero, FJ (eds.), Fusion of Cultures. Proceedings of the 38th Annual Conference on Computer Applications and Quantitative Methods in Archaeology, Granada, Spain, April 2010. BAR International Series. Oxford: Archaeopress. pp. 375-382.

Hesse, R. 2013. The changing picture of archaeological landscapes: lidar prospection over very large areas as part of a cultural heritage strategy. In Opitz, R and Cowley, D (eds.), Interpreting archaeological topography: lasers, 3D data, observation, visualisation and applications, pp. 171-183. DOI: https://doi. org/10.2307/j.ctvh1dqdz.19

Hiebel, G, Doerr, M, Eide, Ø and Theodoridou, M. 2015. CRMgeo: a Spatiotemporal Model. An Extension of CIDOC CRM to link the CIDOC CRM to GeoSPARQL through a Spatiotemporal Refinement. Proposal for approval by CIDOC CRM-SIG (version 1.2). Retrieved 17 December 2017.

Hodder, I. 1999. The archaeological process: an introduction. Oxford: Blackwell.

Ingold, T. 2011. Being alive: Essays on movement, knowledge and description. Routledge. DOI: https://doi. org/10.4324/9780203818336

Laligant, S. 2007. Le labour et le détouré; derrière les techniques se cache la société (Damgan, Morbihan). In: Bourrigaud, R and Sigaut, F (eds.), Nous labourons. Actes du colloque Technique de travail de la terre, hier et aujourd'hui, ici et là-bas. Nantes, Nozay, Châteaubriant 25-28 octobre 2006. Nantes: Éditions du Centre d'histoire du travail. pp. 117-132. 
Laurence, R. 1999. The Roads of Roman Italy: Mobility and Cultural Change. London: Routledge.

Lefebvre, H. 1974. La production de l'espace. Paris: Éditions Anthropos. DOI: https://doi.org/10.3406/ homso.1974.1855

Leturcq, S. 2008. Fonction et devenir d'un réseau invisible: les crêtes de labours dans les terroirs beaucerons (XIVeXXe siècles). In: Compatangelo-Soussignan, R, Bertrand, J-R, Chapman, J and Laffont, P-Y (eds.), Marqueurs des paysages et systemes socio-economiques. 2008 Rennes: Presses universitaires de Rennes. pp. 163-174.

Llobera, M. 1996. Exploring the topography of mind: GIS, social space and archaeology. Antiquity, 70(269): 612-622. DOI: https://doi.org/10.1017/ S0003598X00083745

Llobera, M. 2000. Understanding movement: a pilot model towards the sociology of movement. In: Lock, G (ed.), Beyond the Map. Archaeology and Spatial Technologies. NATO Science Series. Series A: Life Sciences. Amsterdam: IOS Press/Ohmsha. pp. 66-84.

McCoy, MD and Ladefoged, TN. 2009. New developments in the use of spatial technology in archaeology. Journal of Archaeological Research, 17(3), 263-295. DOI: https://doi.org/10.1007/s10814-009-9030-1

McOmish, D. 2011. Introductions to Heritage Assets: Field Systems. English Heritage, 1-5.

Mlekuž, D. 2013. Messy landscapes: lidar and the practices of landscaping. In: Opitz, RS and Cowley, DC (eds.), Interpreting archaeological topography. 3D data, visualisation and observation. AARG Occasional Paper. Oxford: Oxbow Books. pp. 88-99. DOI: https://doi.org/10.2307/j.ctvh1dqdz.12

Mlekuž, D. 2014. Exploring the topography of movement. In: Polla, S and Verhagen, P (eds.), Computational Approaches to the Study of Movement in Archaeology. Theory, Practice and Interpretation of Factors and Effects of Long Term Landscape Formation and Transformation. Topoi - Berlin Studies of the Ancient World/Topoi - Berliner Studien der Alten Welt. Berlin: De Gruyter. pp. 5-22.

Murrieta-Flores, P. 2014. Developing computational approaches for the study of movement: assessing the role of visibility and landscape markers in terrestrial navigation during Iberian Late Prehistory. In: Polla, S and Verhagen, P (eds.), Computational Approaches to the Study of Movement in Archaeology. Theory, Practice and Interpretation of Factors and Effects of Long Term Landscape Formation and Transformation. Topoi - Berlin Studies of the Ancient World/Topoi - Berliner Studien der Alten Welt. Berlin: De Gruyter. pp. 99-132.

Nicolucci, F. 2017. Documenting archaeological science with CIDOC CRM. International Journal on Digital Libraries, 18(3): 223-231. DOI: https://doi. org/10.1007/s00799-016-0199-x

Opitz, RS and Cowley, DC (eds.). 2013. Interpreting archaeological topography. Airborne laser scanning, 3D data and ground observation. Occasional Publication of the Aerial Archaeology Research Group. Oxford: Oxbow Books.
Opitz, RS and Johnson, TD. 2016. Interpretation at the controller's edge: Designing graphical user interfaces for the digital publication of the excavations at Gabii (Italy). Open Archaeology, 1(1): 274-290. DOI: https://doi.org/10.1515/opar-2015-0017

Opitz, R and Limp, WF. 2015. Recent developments in high-density survey and measurement (HDSM) for archaeology: implications for practice and theory. Annual Review of Anthropology, 44: 347-364. DOI: https://doi.org/10.1146/ annurev-anthro-102214-013845

Palmer, R. 2013. Reading aerial images. In: Opitz, RS and Cowley, DC (eds.), Interpreting archaeological topography. 3D data, visualisation and observation. AARG Occasional Paper. Oxford: Oxbow Books. pp. 76-87. DOI: https://doi.org/10.2307/j.ctvh1dqdz.11

Piana, P, Balzaretti, R, Moreno, D and Watkins, C. 2012. Topographical art and landscape history: Elizabeth Fanshawe (1779-1856) in early nineteenth-century Liguria. Landscape History, 33(2): 65-82. DOI: https://doi.org/10.1080/01433768.2 012.739397

Ricoeur, P. 1990. Soi-même comme un autre. Paris: Seuil.

Robin, C. 2002. Outside of houses: the practices of everyday life at Chan Nòohol, Belize. Journal of Social Archaeology, 2(2): 245-268. DOI: https://doi. org/10.1177/14605302002002397

Shaw, LC. 2012. The Elusive Maya Marketplace: An Archaeological Consideration of the Evidence. Journal of Archaeological Research, 20(2): 117-155. DOI: https://doi.org/10.1007/s10814-011-9055-0

Sheth, A and Perry, M. 2008. Traveling the semantic web through space, time, and theme. IEEE Internet Computing, 12(2): 81-86. DOI: https://doi.org/10.1109/ MIC.2008.46

Small, F. 2016. The lost Roman road from Chichester to Arundel. Historic England Research. Uncovering our urban wetlands, 4: 2-8. https://historicengland.org.uk/images-books/publications/ historic-england-research-4.

Tolk, A and Muguira, JA. 2003. The Levels of Conceptual Interoperability Model. In: 2003 Fall Simulation Interoperability Workshop, Orlando, Florida, September 2003. Orlando: Simulation Interoperability Standards Organization.

Trier, ØD, Zortea, M and Tonning, C. 2015. Automatic detection of mound structures in airborne laser scanning data. Journal of Archaeological Science: Reports, 2: 69-79. DOI: https://doi.org/10.1016/j. jasrep.2015.01.005

van Lanen, RJ, Kosian, MC, Groenewoudt, BJ, Spek, T and Jansma, E. 2015. Best travel options: Modelling Roman and early-medieval routes in the Netherlands using a multi-proxy approach. Journal of Archaeological Science: Reports, 3: 144-159. DOI: https://doi.org/10.1016/j.jasrep.2015.05.024

Verbrugghe, G, De Clercq, W and Van Eetvelde, V. 2017. Routes across the Civitas Menapiorum: using least cost paths and GIS to locate the Roman roads of Sandy Flanders. Journal of Historical Geography, 
57: 76-88. DOI: https://doi.org/10.1016/j. jhg.2017.06.006

Verhagen, P and Jeneson, K. 2012. A Roman Puzzle. Trying to Find the Via Belgica with GIS. In: Chrysanthi, A, Murrieta Flores, P and Papadopoulos, C (eds.), Thinking beyond the Tool: Archaeological Computing \& the Interpretive Process. BAR International Series. Oxford: Archaeopress. pp. 123-130.

Verhagen, P, Nuninger, L and Groenhuijzen, MR. 2019. Modelling of pathways and movement networks in archaeology: an overview of current approaches. In: Verhagen, P, Joyce, J and Groenhuijzen, MR (eds.), Finding the Limits of the Limes: Modelling Demography, Economy and Transport on the Edge of the Roman Empire. Cham: Springer. pp. 217-249. DOI: https://doi.org/10.1007/978-3-030-04576 $-0 \_11$

Verschoof-van der Vaart, W and Lambers, K. 2019. Learning to Look at LiDAR: The Use of R-CNN in the Automated Detection of Archaeological Objects in LiDAR Data from the Netherlands. Journal of Computer Applications in Archaeology, 2(1): 31-40. DOI: https://doi.org/10.5334/jcaa.32

Vletter, WF. 2014. (Semi) automatic extraction from Airborne Laser Scan data of roads and paths in forested areas. In: Hadjimitsis, DG, Themistocleous, K, Michaelides, S and Papadavid, G (eds.), Proceedings of SPIE 2014. pp. 92291D-1. DOI: https://doi. org/10.1117/12.2069709

Vletter, WF and van Lanen, RJ. 2018. Finding Vanished Routes: Applying a Multi-modelling Approach on Lost Route and Path Networks in the Veluwe Region, the Netherlands. Rural Landscapes:
Society, Environment, History, 5(1): 2. DOI: https:// doi.org/10.16993/rl.35

Whitley, TG and Hicks, LM. 2003. A geographic information systems approach to understanding potential prehistoric and historic travel corridors. Southeastern Archaeology, 22: 77-91.

Whitley, TG, Moore, G, Goel, G and Jackson, D. 2010. Beyond the Marsh: Settlement Choice, Perception and Spatial Decision-Making on the Georgia Coastal Plain. In: Frischer, B, Webb Crawford, J and Koller, D (eds.), Making History Interactive. Computer Applications and Quantitative Methods in Archaeology (CAA). Proceedings of the 37th International Conference, Williamsburg, Virginia, United States of America, March 22-26, 2009. Oxford: Archaeopress. pp. 380-390.

Williamson, T. 2016. The ancient origins of medieval fields: A reassessment. Archaeological Journal, 173(2): 264-287. DOI: https://doi.org/10.1080/00 665983.2016 .1191129

Zadora-Rio, E. 1991. Les terroirs médiévaux dans le Nord et le Nord-Ouest de l'Europe. In: Guilaine, J (ed.), Pour une archéologie agraire: à la croisée des sciences de l'homme et de la nature. Paris: A. Colin. pp. 165-192.

Zakšek, K, Fovet, É, Nuninger, L and Pobodnikar, T. 2008. Path Modelling and Settlement Pattern. In: Posluschny, A, Lambers, K and Herzog, I (eds.), Layers of Perception. Proceedings of the 35th International Conference on Computer Applications and Quantitative Methods in Archaeology (CAA), Berlin, Germany, April 2-6, 2007. Kolloquien zur Vor- und Frühgeschichte. Bonn: Dr. Rudolf Habelt GmbH. pp. 309-315.

\begin{abstract}
How to cite this article: Nuninger, L, Opitz, R, Verhagen, P, Libourel, T, Laplaige, C, Leturcq, S, Le Voguer, N, Fruchart, C, Kokalj, ̌̌ and Rodier, X. 2020. Developing FAIR Ontological Pathways: Linking Evidence of Movement in Lidar to Models of Human Behaviour. Journal of Computer Applications in Archaeology, 3(1), pp. 63-75. DOl: https://doi.org/10.5334/jcaa.46
\end{abstract}

Submitted: 01 November $2019 \quad$ Accepted: 24 March $2020 \quad$ Published: 15 April 2020

Copyright: $(2020$ The Author(s). This is an open-access article distributed under the terms of the Creative Commons Attribution 4.0 International License (CC-BY 4.0), which permits unrestricted use, distribution, and reproduction in any medium, provided the original author and source are credited. See http://creativecommons.org/licenses/by/4.0/.

] $\mathrm{u}$ Journal of Computer Applications in Archaeology, is a peer-reviewed open access journal published by Ubiquity Press.

OPEN ACCESS $\odot$ 